\title{
Benign meningioma with complete erosion of the skull in a 38-year-old Ghanaian woman
}

\author{
E.M. Der*1, R. Mikdad², B.J. Leuri ${ }^{3}$, A. Adam ${ }^{4}$ \\ ${ }^{1}$ Department of Pathology, School of Medicine and Health Sciences, University for Development Studies, Tamale, Ghana \\ ${ }^{2}$ Department of Pathology, Tamale Teaching Hospital, Tamale, Ghana \\ ${ }^{3}$ Accident and Emergency Unit, Tamale, Ghana \\ ${ }^{4}$ Department of Surgery, School of Medicine and Health Sciences, UDS; Neurosurgical Unit, Tamale Teaching Hospital, Tamale, \\ Ghana
}

Received: March 9, 2017

Accepted: May 19, 2017

Online Published: June 2, 2017

DOI: $10.5430 /$ jst.v7n2p34

URL: https://doi.org/10.5430/jst.v7n2p34

\begin{abstract}
Meningioma is common intracranial benign tumour, but may be diagnosed only at autopsy in developing countries. We present a 38-year-old woman with progressively worsening headache of 7 years duration, who had sudden onset of inability to walk, vomiting and loss of consciousness. She died shortly on admission at the Tamale Teaching Hospital emergency unit. Autopsy conducted found an encapsulated left cerebral hemisphere convexity tumour that had eroded the skull with extension onto the scalp as a swelling. Histological examination confined the tumour to WHO grade I, meningioma.
\end{abstract}

Key Words: Meningioma, Ghana, Tamale, Female, Autopsy, Convexity tumour, WHO grade 1

\section{INTRODUCTION}

Meningioma is the most common intracranial tumour arising from the pia-arachnoid matter in humans from clinical and autopsy studies. ${ }^{[1-3]}$ Meningiomas are common within the 40-60 year age group ${ }^{[6,7]}$ and more so in females black patients. ${ }^{[4-7]}$ The common locations are convexity, parasagital, falx, ventricular and tentorium. ${ }^{[8,9]}$ These intracranial tumours produce their symptoms by several mechanisms depending on the size and the location. They may cause symptoms by irritating the underlying cortex, compressing the brain or the cranial nerves, producing hyperostosis and/or invading the overlying soft tissues, or inducing vascular injuries to the brain. ${ }^{[10,11]}$ We present a case report of a left cerebral hemisphere convexity meningioma with erosion of the skull and infiltration of the scalp in a 38-year-old Ghana- ian woman.

\section{Case PResentation}

Deceased DJ, a 38-year-old Ghanaian woman presented to the accident and emergency room of the Tamale Teaching Hospital at about 3:30 AM with severe headache associated with sudden onset of vomiting, inability to walk and loss of consciousness. The symptoms started 7 years ago as generalized headaches of mild severity, but progressively worsen with time until she was unable to speak, unable to walk and had to be carried to the hospital for treatment. She has been to several health facilities with complains of headache and had also used herbal medicine without improvement. There was no associated aggravating or relieving factors. She has no history of hypertension.

\footnotetext{
*Correspondence: E.M. Der; Email: maadelle@yahoo.com; Address: Department of Pathology, School of Medicine and Health Sciences, University for Development Studies, Tamale Teaching Hospital, Tamale, Ghana.
} 
Physical examination at the accident emergency room reveals a young female adult lying restless, in respiratory distress, warm to touch $\left(38.7^{\circ} \mathrm{C}\right)$, not pale, not jaundice and acyanotic. Glasgow coma scale (GCS) was 8/15 on arrival (Eye opening $=1$, Best verbal response $=1$, Best motor response $=$ 6). She had increased muscle tone in all the limbs (rigidity). The blood pressure was $130 / 90 \mathrm{mmHg}$ with a pulse rate of $88 \mathrm{bpm}$. There was reduced air entry in all the lung fields with bilateral coarse crepitation. Computer tomography (CT scan) was requested but not done due lack of funds.

\subsection{Initial working diagnosis}

1) Intracranial haemorrhage; 2)Intracranial haemorrhage; 3)Meningitis.

\subsection{Initial management}

The patient was managed with intravenous morphine, metoclopramide, ceftriaxone and suppository diclofenac.

\subsection{Investigations}

The following investigations were requested for but were not done because patient died shortly on admission.

(1) Full blood count with differentials.

(2) Thick blood film for malaria parasites.

(3) Computer tomography of the head (CT scan).

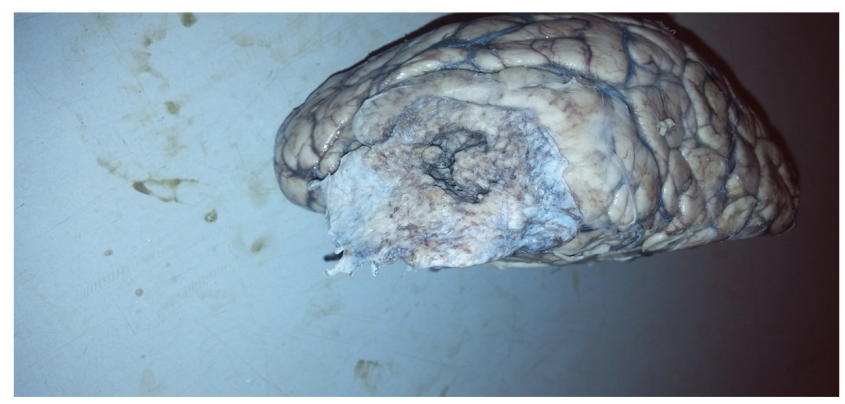

Figure 1. Superior view of the left cerebral hemisphere showing a meningioma with surrounding cerebral oedema

\section{Results}

\subsection{Autopsy findings: The brain}

Externally, there was a firm left scalp swelling measuring $12.0 \mathrm{~cm} \times 9.5 \mathrm{~cm} \times 2.0 \mathrm{~cm}$. Dissecting the head showed an encapsulated tan nodular extra-cerebral convexity tumour measuring $10.0 \mathrm{~cm} \times 8.0 \mathrm{~cm} \times 6.5 \mathrm{~cm}$, with compression of the adjacent brain parenchyma. The tumour had eroded through the calvarian with infiltration of the scalp (swelling). The brain weighed 1,500 $\mathrm{g}$ with tonsilar and tentorial herniations. Cut surface of the tumour was tan to reddish brown. The rest of the brain parenchyma shows oedema and fibrosis (see Figures 1 and 2).

Published by Sciedu Press

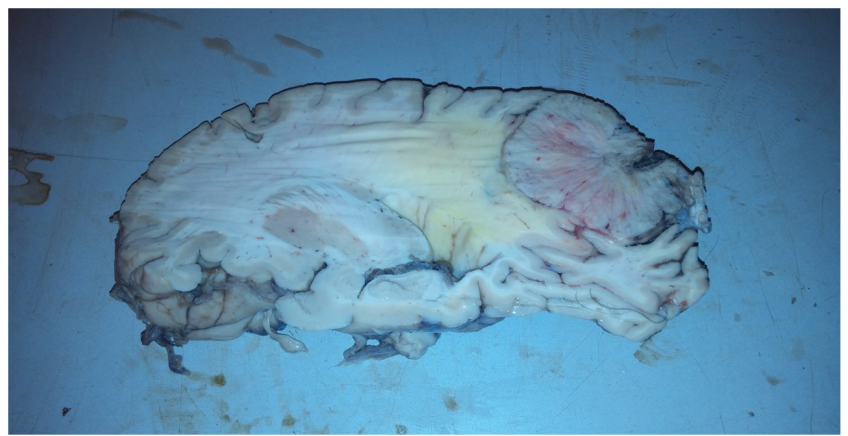

Figure 2. Sagittal section of the left cerebral hemisphere showing a well-defined convexity meningioma with compression of the surrounding brain parenchyma

\subsection{Histology of the brain tumour stained with haema- toxylin and eosin (H\&E)}

Sections of the intracranial tumour showed meningothelial cells with round, oval and elongated nuclei with indistinct nucleoli. The cells had predominantly whorl pattern of growth. Scattered within the tumour were psammoma bodies (see Figure 3).

Histological diagnosis: WHO grade 1 mesothelial meningioma.

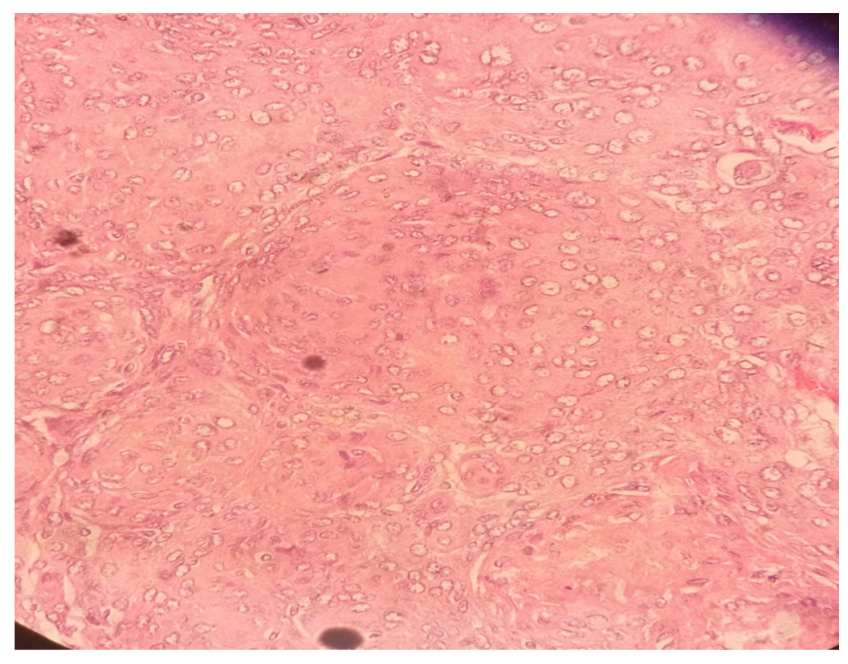

Figure 3. H\&E section of a meningothelial meningioma (WHO grade 1) with whorled pattern of growth and scattered psammoma bodies

\section{Discussion}

Deceased madam DJ, a 38-year-woman was rushed to the Tamale Teaching Hospital emergency room with sudden onset of inability to walk, vomiting and unconsciousness. These 
symptoms were preceded by a history of prolonged and progressively worsening headache (over 7 years) for which she had visited several health facilities including the herbalists. She died shortly on admission. Examination of the brain at autopsy revealed a well-defined tan nodular convexity extracerebral tumour firmly attached to dura mater associated with cerebral oedema and herniations. The tumour was diagnosed histological as WHO grade 1 meningioma. The age and gender characteristics of this case report were in accordance with published literature that found meningioma to be common in females, particularly between the ages of 40 to 60 years. ${ }^{\text {[-7] }}$ It has been said that females were more vulnerable to the factors that predispose to meningioma formation such as sex hormones, trauma and radiations. ${ }^{[6,7]}$

The gross appearance and the location of meningioma in case report support those of previous studies. ${ }^{[8,9]}$ Meningiomas are slow growing tumours with the resultant space occupying lesion effects and hence raised intracranial pressure. ${ }^{\text {[9-11] }}$ The clinical presentation of meningioma had been found to relate to tumour size and location. ${ }^{\left[{ }^{9-11]}\right.}$ Grossly the tumour in this current report was found to be $10 \mathrm{~cm}$ in the widest dimension with compression of the adjacent brain parenchyma. The progressively worsening headaches, the inability to talk, walk associated with vomiting and unconsciousness were manifestations of the mass (compression) effects of the tumour and hence raised intracranial pressure. The sudden death in this case could also have been potentiated by the inappropriate use of morphine.

At autopsy, the tumour was found to have eroded through the skull into the scalp as a swelling. Skull erosion by meningioma has been reported in the literature. ${ }^{[12-15]}$ The presentation of meningioma as a scalp lump was however uncommon and commonly an indication of a long standing condition or a neglected medical complaint.
What are the lessons to be learnt from this case report?

Delay presentation, lack of funds to afford appropriate neurological services and inadequate manpower for prompt diagnosis and management of neoplastic lesions still persists in our environment. Secondly, our peculiar cultural and religious beliefs commonly prevent patient for seeking health at the health facilities early enough for prompt diagnosis and management as can be seen in this case report. In this regards preventable deaths become unpreventable in most developing countries like Ghana. For instance, if the diagnosis of meningioma was made early enough and not at autopsy, Madam DJ condition could have been managed surgically by excision as being done in the more resourceful and developed countries, since in her case there was no brain invasion. Furthermore, headache of progressively increasing severity requires a diagnostic work-up which should include CT scan which helps to show the skull involvement (erosion) and the nature of the soft tissue, magnetic resonance imaging (MRI) which will show any intracranial extension and finally a tissue biopsy is needed to establish a tissue diagnosis.

\section{Conclusions}

Headache is a common (differential diagnosis) symptom of intracranial lesion, but when progressive with deteriorating health, always points to an underlying organic condition, requiring prompt and detail investigations and management.

\section{CONFLicts OF InTEREST Disclosure}

The authors declare that there is no conflict of interest statement.

\section{ACKNOWLEDGEMENTS}

We wish to express our profound gratitude to all the mortuary staff of the Tamale Teaching Hospital for the valuable support during the autopsy.

\section{REFERENCES}

[1] Campbell BA, Jhamb A, Maguire JA, et al. Meningiomas in 2009: Controversies and Future Challenges. A J Clin Oncol. 2009; 32 73-85. PMid:19194129. https://doi.org/10.1097/COC.0b01 3e31816f c920

[2] Wiemels J, Wrensch M, Claus EB. Epidemiology and etiology of meningioma. J Neuro oncol. 2010; 99: 307-14. PMid:20821343. https : //doi.org/10.1007/s11060-010-0386-3

[3] Takano N, Asano K, Miura H, et al. Meningiomas with brain oedema: Radiological characteristics and review of the literature. Clinical Imaging. 2002; 26: 243-9.

[4] Rao A, Agrino A, Gagnardi FM, et al. Surgical options in the management of fal-comeningiomas: report of 13 cases. Surg Neurol. 2004; 61: 157-64. urlhttps://doi.org/10.1016/S0090-3019(03)00573-1

[5] Black PM. Meningiomas. Neurosurgery. 1993; 32: 643-57.
PMid:8474655. https ://doi.org/10.1227/00006123-19930 4000-00023

[6] Fynn E, Khan N, Ojo A. Meningioma - a review of 52 cases. South African Journal of Radiology. 2004; 8(4). https : //doi .org/10.4 102/sajr.v8i4.100

[7] Ibebuike K, Ouma J, Gopal R. Meningiomas among intracranial neoplasms in Johannesburg, South. Afr Health Sci. 2013; 13: 118-21. PMid:23658577.

[8] Ruberti RF. The Surgery of Meningiomas: a review of 215 cases. AJNS. 2016: 2.

[9] Vivier J, Bardien S, Van der Merwe L, et al. A study of meningiomas in South Africa: investigating a correlation between clinical presentation, histopathology and genetic markers. Br J Neurosurg. 2009; 23 : 63-70. PMid:19234911. https://doi .org/10.1080/02688690 802593064 
[10] Pieper DR, Al-Mefty O, Hanada Y, et al. Hyperostosis associated with meningioma of the cranial base: secondary changes or tumor invasion. Neurosurgery. 1999; 44: 742-6. PMid:10201298. https://doi.org/10.1097/00006123-199904000-00028

[11] Hallinan JT, Hegde AN, Lim WE. Dilemmas and diagnostic difficulties in meningioma. Clin Radiol. 2013 Aug; 68(8): 837-44. PMid:23623578. https://doi.org/10.1016/j.crad.2013.03 .007

[12] Pendergrass EP, Hope JW. An extracranial meningioma with no apparent intracranial source. Am J Roentgenol Radium Ther Nucl Med. 1953; 70: 967-70. PMid:13104730.
[13] Oka K, Hirakawa K, Yoshida S, et al. Primary calvarial meningioma Surg Neurol. 1989; 32: 304-10. https://doi.org/10.1016/00 90-3019(89) 90235-8

[14] Ghobashy A, Tobler W. Intraosseous calvarial meningioma of the skull presenting as a solitary osteolytic skull lesion. Acta Nerochir (Wein). 1994; 129: 105-8. https://doi.org/10.1007/BF0140 0883

[15] McWhorter JM, Ghatak NR, Kelly DL. Extracranial meningioma presenting as lytic skull lesion. Surg Neurol. 1976; 5: 223-4. PMid:1265631. 